J. Dairy Sci. 92:870-886

doi:10.3168/jds.2008-1457

(C) American Dairy Science Association, 2009.

\title{
Temporal gene expression and probiotic attributes of Lactobacillus acidophilus during growth in milk
}

\author{
M. A. Azcarate-Peril, ${ }^{1}$ R. Tallon, ${ }^{2}$ and T. R. Klaenhammer ${ }^{3}$ \\ Department of Food, Bioprocessing, and Nutrition Sciences, and Southeast Dairy Foods Research Center, North Carolina State University, \\ Raleigh 27695
}

\begin{abstract}
Lactic acid bacteria have been used as starter strains in the production of fermented dairy products for centuries. Lactobacillus acidophilus is a widely recognized probiotic bacteria commonly added to yogurt and used in dietary supplements. In this study, a whole genome microarray was employed to monitor gene expression of $L$. acidophilus NCFM cells propagated in $11 \%$ skim milk during early, mid and late logarithmic phase, and stationary phase. Approximately $21 \%$ of 1,864 open reading frames were differentially expressed at least in one time point. Genes differentially expressed in skim milk included several members of the proteolytic enzyme system. Expression of prtP (proteinase precursor) and prtM (maturase) increased over time as well as several peptidases and transport systems. Expression of Opp1 (oligopeptide transport system 1) was highest at $4 \mathrm{~h}$, whereas gene expression of Opp2 increased over time reaching its highest level at $12 \mathrm{~h}$, suggesting that the 2 systems have different specificities. Expression of a 2-component regulatory system, previously shown to regulate acid tolerance and proteolytic activity, also increased during the early log and early stationary phases of growth. Expression of the genes involved in lactose utilization increased immediately ( $5 \mathrm{~min}$ ) upon exposure to milk. The acidification activity, survival under storage conditions, and adhesion to mucin and Caco-2 tissue culture cells of selected mutants containing insertionally inactivated genes differentially expressed in the wild-type strain during growth in milk were examined for any potential links between probiotic properties and bacterial growth and survival in milk. Some of the most interesting genes found to be expressed in milk were correlated with signaling (autoinducer-2) and adherence to mucin and intestinal epithelial cells, in vitro.
\end{abstract}

\footnotetext{
Received June 15, 2008.

Accepted November 5, 2008.

${ }^{1}$ Current address: Department of Cell and Molecular Physiology, University of North Carolina at Chapel Hill, Chapel Hill, North Carolina.

${ }^{2}$ Current address: SAF-ISIS, Aquitaine, France.

${ }^{3}$ Corresponding author: klaenhammer@ncsu.edu
}

Key words: Lactobacillus acidophilus, probiotic, microarray analysis, dairy

\section{INTRODUCTION}

Lactic acid bacteria (LAB) constitute a varied group of microorganisms that occur naturally in dairy, meat, and plants (cabbage, corn, barley, mashes, kale, and silage; Carr et al., 2002). The most important application of LAB has been their use as starter cultures in the manufacture of fermented foods, and notably dairy products such as cheese, yogurt, and fermented milk. Today, the dominant vehicles for delivery of probiotic strains in foods are yogurt and fermented milk. Lactobacillus acidophilus is a widely recognized probiotic bacteria commonly added to yogurt (Sanders and Klaenhammer, 2001), with approximately $80 \%$ of the yogurt in the United States now containing L. acidophilus (Hutkins, 2006). Although this microorganism does not participate in the actual yogurt fermentation, it grows slowly in milk during product manufacture (Shah, 2000). Consequently, it is a common practice to incorporate yogurt cultures (Lactobacillus delbrueckii ssp. bulgaricus and Streptococcus thermophilus) along with probiotic cultures (L. acidophilus, Lactobacillus casei, Lactobacillus reuteri, and Bifidobacterium spp.) in many yogurts and fermented milks (Shah, 2000).

Probiotics are "live microorganisms which, when administered in adequate amounts, confer a health benefit on the host" (Reid et al., 2003). The International Dairy Federation recommends that dairy products contain at least $10^{7} \mathrm{cfu} / \mathrm{mL}$ (Champagne et al., 2005). The actual number of colony-forming units that reach the distal portion of the gastrointestinal tract remains debatable, but clearly depends on several aspects that include acid and bile tolerance of the probiotic strain, manufacturing conditions, and survival of the microorganism during the fermentation and postfermentation (cooling and storage) stages. The major factor affecting viability and performance of probiotic strains during processing is the food matrix formulation (Mattila-Sandholm et al., 2002). Additionally, survival of probiotic strains during storage is a key issue in the food industry. Several stud- 
Table 1. Strains and plasmids used in this study

\begin{tabular}{|c|c|c|c|}
\hline Strain & Characteristics & $\begin{array}{l}\text { Inactivated } \\
\text { gene }\end{array}$ & Reference or source \\
\hline \multicolumn{4}{|c|}{ Lactobacillus acidophilus } \\
\hline $\mathrm{NCFM}^{1}$ & Human intestinal isolate & & Barefoot and Klaenhammer (1983) \\
\hline NCK1375 & NCFM integrant $c d p \mathrm{~A}:: \mathrm{pTRK} 828$ & LBA0175 & Altermann et al. (2004) \\
\hline NCK1624 ${ }^{1}$ & NCFM integrant treE::pTRK801 & LBA1012 & Duong et al. (2005) \\
\hline NCK1746 & NCFM integrant $m d o B:: p T R K 842$ & LBA0447 & $\begin{array}{l}\text { Pfeiler (North Carolina State University); } \\
\text { unpublished results }\end{array}$ \\
\hline NCK1618 & NCFM integrant $b s h \mathrm{~A}::$ pTRK734 & LBA0892 & McAuliffe et al. (2005) \\
\hline NCK1765 & NCFM integrant luxS::pTRK854 & LBA1081 & Buck et al. (2008); in press \\
\hline NCK1661 & NCFM integrant $f b p$ A::pTRK833 & LBA1148 & Buck et al. (2005) \\
\hline NKC1376 & NCFM integrant $c f a:$ pTRK697 & LBA1274 & $\begin{array}{l}\text { Courtney et al. (North Carolina State University); } \\
\text { unpublished results }\end{array}$ \\
\hline NCK $1660^{1}$ & NCFM integrant $m u b:: p T R K 834$ & LBA1392 & Buck et al. (2005) \\
\hline NCK1822 ${ }^{1}$ & NCFM integrant surface exclusion protein::pTRK886 & LBA1690 & This study \\
\hline NCK1816 & NCFM integrant noncoding region::pTRK883 & none & $\begin{array}{l}\text { Buck (North Carolina State University); } \\
\text { unpublished results }\end{array}$ \\
\hline NCK1728 & NCFM $\Delta$ frc & LBA0395 & Azcarate-Peril et al. (2006) \\
\hline NCK1392 & NCFM containing pTRK669 & none & Russell and Klaenhammer (2001) \\
\hline $\begin{array}{l}\text { Escherichia coli } \\
\text { EC1000 }\end{array}$ & RepA $^{+}$MC1000, $\mathrm{Km}^{\mathrm{r}}$; host for pORI28-based plasmids & & Law et al. (1995) \\
\hline
\end{tabular}

${ }^{1}$ Strains selected for adhesion experiments to mucin and Caco-2 tissue culture cells.

ies (reviewed by Champagne et al., 2005) have reported that $\mathrm{pH}$, oxygen, and starter production conditions have significant effects on survival and stability of probiotic cultures during storage in yogurt.

The selection criteria for probiotics include general safety and stability aspects and functional properties (Tuomola et al., 2001). To survive passage through the stomach and small intestine, probiotic strains must tolerate the acidic and digestive protease conditions of the stomach, and must survive and grow in the presence of bile acids. The ability to adhere to the mucosa and intestinal tissues has been related to retention in the gastrointestinal tract and immunomodulation (Grangette et al., 2005; Hisbergues et al., 2007). In this regard, L. acidophilus NCFM, delivered widely in yogurt and fermented milks, has been shown to adhere to enterocyte-like Caco-2 cells via cell surface proteins such as a fibronectin-binding protein, a mucin-binding protein, and a surface layer protein (Buck et al., 2005).

Milk is the dominant food vehicle and substrate for delivery of probiotic strains to humans. Our objective was to investigate how growth in milk affected gene expression in L. acidophilus NCFM and determine if any potential probiotic traits were affected during exposure to, and fermentation of, milk.

\section{MATERIALS AND METHODS}

\section{Strains, Plasmids, and Culture Conditions}

The bacterial strains used in this study are listed in Table 1. Escherichia coli were propagated at $37^{\circ} \mathrm{C}$ in Luria-Bertani broth (Difco Laboratories Inc., Detroit, MI) with shaking. Escherichia coli cultures were propagated on brain heart infusion agar (Difco), supplemented with $150 \mu \mathrm{g}$ of erythromycin/mL, when appropriate. Lactobacilli were propagated statically at $37^{\circ} \mathrm{C}$ in de Man, Rogosa, and Sharpe broth (MRS; Difco), or MRS agar supplemented with $1.5 \%$ agar. When appropriate, erythromycin $(5.0 \mu \mathrm{g} / \mathrm{mL})$ or chloramphenicol $(4.0 \mu \mathrm{g} / \mathrm{mL})$ was added to MRS broth or agar plates. For growth and microarray experiments, L. acidophilus was propagated at $37^{\circ} \mathrm{C}$ in $11 \%$ reconstituted skim milk (SM; MP Biomedicals Inc., Solon, OH). After reconstitution, the milk was steamed at $100^{\circ} \mathrm{C}$ for $40 \mathrm{~min}$ and immediately placed in an ice bath.

\section{Genetic Constructions}

Construction of the L. acidophilus NCFM::LBA1690 mutant was carried out according to the method described by Russell and Klaenhammer (2001). A 688- 
bp internal fragment of open reading frame (ORF) LBA1690 was amplified by PCR using L. acidophilus NCFM chromosomal DNA as a template and the primers I1690F (5'-GATCTCTAGATCAAGCTGCATCAATTAC-3') and I16904R (5'-GATCAGATCTTGTGAACACTAATCTTAC-3'). The amplified fragment was cloned into the integrative vector pORI28 (Law et al., 1995) generating pTRK886, which was then introduced by electroporation in L. acidophilus NCFM (pTRK669). Subsequent steps to facilitate the integration event were carried out as described previously (Russell and Klaenhammer, 2001). Integrants were confirmed by PCR and Southern hybridization analysis using standard procedures (data not shown).

\section{Microarray Experimental Design and RNA Isolation}

A loop experimental design (Vinciotti et al., 2005) was employed in a time course experiment to monitor the transcriptional response of L. acidophilus NCFM during growth in $11 \%$ reconstituted skim milk. The culture was initiated in MRS broth and transferred 3 to 5 times in SM before a $10 \%$ inoculation in prewarmed SM. Cells and RNA samples were obtained from 2 biological replicates at times of $5 \mathrm{~min}(\mathrm{pH}=6.4 ; \approx 2.1 \times$ $\left.10^{7} \mathrm{cfu} / \mathrm{mL}\right), 4 \mathrm{~h}\left(\mathrm{pH}=5.8 ; \approx 3.8 \times 10^{7} \mathrm{cfu} / \mathrm{mL}\right), 8 \mathrm{~h}$ $\left(\mathrm{pH}=5.4 ; \approx 7.1 \times 10^{7} \mathrm{cfu} / \mathrm{mL}\right)$, and $12 \mathrm{~h}(\mathrm{pH}=4.9 ; \approx$ $1.5 \times 10^{8} \mathrm{cfu} / \mathrm{mL}$; see Supplementary Figure 1 available online: http://jds.fass.org/content/vol92/issue3/) and compared in an unbalanced loop-design. Samples were compared as follows (by dye used, Cy3 versus Cy5; Amersham Biosciences, Piscataway, NJ): T1 (5 min) versus T2 $(4 \mathrm{~h})$, T2 versus T3 ( $8 \mathrm{~h})$, T3 versus T4 (12 h), T4 versus T2, and T3 versus T1. One-hundred-milliliter aliquots of $L$. acidophilus cells growing in SM were harvested by centrifugation for $10 \mathrm{~min}$ at $3,220 \times g$, and frozen immediately in a dry ice/ethanol bath (the total time of each sampling process was $5 \mathrm{~min}$ ). Isolation of RNA was performed as described previously (AzcaratePeril et al., 2005) with the following modifications: 5 $\mathrm{mL}$ of Trizol reagent (Invitrogen, Carlsbad, CA) was added to the cell pellets and they were homogenized in a Mini-Beadbeater-8 cell disruptor (Biospec Products, Bartlesville, OK) for seven 40-s cycles (and chilled on ice for $40 \mathrm{~s}$ between cycles); the phases were then separated by centrifugation $\left(3,220 \times g\right.$ for $20 \mathrm{~min}$ at $\left.4^{\circ} \mathrm{C}\right)$. The aqueous phase was removed to a fresh tube and 2.1 $\mathrm{mL}$ of Trizol and $1 \mathrm{~mL}$ of chloroform were added. The mixture was vortexed for $15 \mathrm{~s}$ and centrifuged $(3,220 \times$ $g$ for $15 \mathrm{~min}$ at $4^{\circ} \mathrm{C}$ ) to separate the phases. The Trizol step was repeated twice and RNA was precipitated from the final aqueous phase by adding 1 volume of isopropanol, followed by incubation at room temperature for $10 \mathrm{~min}$ and centrifugation $(11,600 \times g$ for $10 \mathrm{~min}$ at $4^{\circ} \mathrm{C}$ ). Purity and quality of RNA samples were determined by electrophoresis on agarose gels. NanoDrop (ND-3300, NanoDrop Technologies, Wilmington, DE) was used as an ultraviolet/visual spectrophotometer for quantification of the RNA samples.

\section{Microarray Hybridization}

A previously developed and validated microarray platform based on the PCR products of predicted ORF from L. acidophilus NCFM (Azcarate-Peril et al., 2005) was used to monitor changes in gene expression. Reverse transcription and labeling of identical amounts $(20 \mu \mathrm{g})$ of DNase-treated (Invitrogen) RNA was performed with the SuperScript Indirect cDNA Labeling System for DNA Microarrays (Invitrogen) according to the manufacturer's directions. Coupling of the $\mathrm{Cy} 3$ and Cy5 dyes to the aa-dUTP (2'-deoxyuridine 5'-triphosphate) labeled cDNA and hybridization of samples to microarrays were performed according to the protocols outlined by Hegde et al. (2000) and described previously (Azcarate-Peril et al., 2005).

\section{Data Preprocessing and Analysis}

After acquisition of fluorescence intensities at 10- $\mu \mathrm{m}$ resolution using a ScanArray 4000 Microarray Scanner (Packard Biochip BioScience; Biochip Technologies LLC, Billerica, MA), signal intensities (stored as TIFF files) were quantified, and the local background was subtracted using the QuantArray 3.0 software package (Packard BioScience). Afterwards, data were $\log _{2}$ transformed and imported into JMP Genomics (SAS, Cary, $\mathrm{NC}$ ). Loess normalization was applied to preprocessed data. Following normalization, gene-specific effects were modeled in terms of the residuals. A mixed model analysis was applied to the prenormalized data (Cui and Churchill, 2003). False discovery rate was selected to adjust for the large number of multiple hypothesis tests across all genes. The default value of $\alpha(0.05)$ was used. The model-based approach, step-down quadratic regression method was applied to 791 significant genes for pattern recognition (Liu et al., 2005).

\section{Microarray Data Submission}

Microarray platform and data are available at the Gene Expression Omnibus (http://www.ncbi.nlm.nih. gov/geo) under accession numbers GPL1401 (platform) and GSE12924 (series).

\section{Real-Time Quantitative PCR}

Real-time quantitative (qRT) PCR was used to confirm microarray results. The protocols described 
previously (Azcarate-Peril et al., 2006) were used for amplification, quantification, and normalization of PCR products. The same RNA samples employed for microarray hybridizations were used for qRT-PCR. The RNA was DNase treated, quantified, and diluted to a concentration of $50 \mathrm{ng} / \mu \mathrm{L}$. The absence of contaminating genomic DNA was confirmed by PCR of the DNase-treated samples. Reverse transcription and PCR were carried out with an iCycler iQ (BioRad Laboratories, Hercules, CA) using the one-step QuantiTect SYBR Green RT-PCR kit (Qiagen, Valencia, CA). Primers meeting the standard criteria for qRT-PCR for the following genes were designed using CloneManager (Scientific \& Educational Software, Cary, NC) software (Supplementary Table 1 available online: http://jds. fass.org/content/vol92/issue3/): LBA0367 (encoding a putative receptor), LBA0395 (formyl-CoA transferase), LBA0396 (oxalyl-CoA decarboxylase), LBA0555 (myosin-crossreactive antigen), LBA1234 (cadmium/ manganese transport ATPase), LBA1249 (heat inducible transcription repressor HrcA), LBA1512 (PrtP precursor), and LBA1588 (PrtM precursor).

The induction ratios measured by microarrays were plotted against induction ratios measured by qRTPCR, for the 8 selected genes and 4 time points, to validate microarray data (Supplementary Table 2 and Supplementary Figure 2 available online: http://jds. fass.org/content/vol92/issue3/). Individual $\mathrm{r}$ values ranged between 0.44 and 0.99 for each of the tested genes with an overall $\mathrm{r}$ value of 0.86 . As reported previously, (Azcarate-Peril et al., 2006), qRT-PCR measurements revealed larger induction levels.

\section{Acidification Activity of L. acidophilus Cultures in Milk}

The acidification capability of L. acidophilus cultures was measured using the Orion EA940 Multi-Channel Benchtop Meter and Multi-Channel Electrode Switchbox (Thermo Fisher Scientific Inc., Waltham, MA). Lactobacillus acidophilus cultures grown overnight in MRS broth were centrifuged $(3,220 \times g$ for $10 \mathrm{~min}$ at room temperature). The pellet was washed twice with phosphate buffer and resuspended in the same buffer. Forty milliliters of prewarmed SM was inoculated with 0.5 to $2.2 \times 10^{7}$ cells. Acidification curves were performed at $37^{\circ} \mathrm{C}$ in $11 \% \mathrm{SM}$. Four independent experiments were performed for each strain and the acidification rate was calculated as the first time derivative. The time in minutes necessary to reach the maximum acidification rate in milk $(\boldsymbol{t} \boldsymbol{m})$ was calculated as described by Fonseca et al. (2000). The $t m$ values were correlated to the natural logarithm of the initial bacterial population (in $\mathrm{cfu} /$ $\mathrm{mL}$ ) as described by Fonseca et al. (2000).

\section{Survival of L. acidophilus Cultures in Acidified Milk}

Survival of L. acidophilus cultures in SM acidified at $\mathrm{pH} 4.5$ (with lactic acid) at $4^{\circ} \mathrm{C}$ was examined as follows. Lactobacillus acidophilus cultures grown overnight in MRS broth at $37^{\circ} \mathrm{C}$ were centrifuged $(3,220 \times g$ for $10 \mathrm{~min}$ at room temperature) and the pellet washed twice with phosphate buffer and resuspended in the same buffer. Fifty milliliters of SM adjusted to $\mathrm{pH} 4.5$ with lactic acid were inoculated with 1.8 to $4.1 \times 10^{8}$ cells. Survival curves were performed at $4^{\circ} \mathrm{C}$. Viable-cell counts were determined at 24 - to 48 -h intervals by plating serial dilutions in a 10\% MRS broth diluent onto MRS agar using a Whitley Automatic Spiral Plater (Don Whitley Scientific Limited, West Yorkshire, England).

\section{Adhesion of L. acidophilus to Mucin}

Mucin and Plate Preparation. The adhesion ability of $L$. acidophilus derivatives was examined by the method of Vishwanath and Ramphal (1984) with minor modifications. One hundred microliters of a 10 $\mathrm{mg} / \mathrm{mL}$ solution of partially purified type III porcine gastric mucin (Sigma Chemical Co., St. Louis, MO) were immobilized in polystyrene 96-well microtiter plates (Corning Inc., Acton, MA) by overnight incubation at $4^{\circ} \mathrm{C}$. Any surplus of mucin was removed by pipetting and wells were washed twice with $200 \mu \mathrm{L}$ of PBS. Adhesion experiments were carried out 3 times, each time in triplicate.

Preparation of Microorganisms for Adhesion Assay. Lactobacillus acidophilus cultures were grown in $\mathrm{SM}$ at $37^{\circ} \mathrm{C}$ until $\mathrm{pH} 6.0$ was reached. One hundred microliters of the bacterial suspension was added to each well and the plates were incubated $1 \mathrm{~h}$ at $37^{\circ} \mathrm{C}$. Each well was washed 7 times with $200 \mu \mathrm{L}$ of sterile PBS (to remove unbound bacteria), then treated with $200 \mu \mathrm{L}$ of a $0.05 \%$ (vol/vol) Triton X-100 solution (to desorb bound bacteria). One hundred microliters of the contents of each well were removed, diluted in PBS, and plated on MRS agar plates. The viability of $L$. acidophilus strains was not affected by Triton X-100 under the conditions used (data not shown). Three wells per sample were used and each adherence assay was conducted in triplicate.

\section{Adhesion to Caco-2 Cells}

The adherence of Lactobacillus strains to epithelial cells was carried out as described by Buck et al. (2005) with the following modifications: Caco-2 cells from passage 24 to 29 were routinely grown in Dulbecco modified Eagle's minimal essential medium (DMEM) 
supplemented with $20 \%$ inactivated fetal bovine serum, $0.1 \mathrm{~m} M$ nonessential amino acids, $1.0 \mathrm{~m} M$ sodium pyruvate, $100 \mathrm{mg} / \mathrm{mL}$ penicillin $\mathrm{G}, 100 \mathrm{mg} / \mathrm{mL}$ streptomycin sulfate and $0.25 \mathrm{mg} / \mathrm{mL}$ amphotericin (Gibco, Invitrogen, Carlsbad, CA). Monolayers of Caco-2 cells were seeded at a concentration of $6.5 \times 10^{4}$ cells per well in 12 -well tissue plates, and incubated at $37^{\circ} \mathrm{C}$ in a $95 \%$ air- $5 \% \mathrm{CO}_{2}$ atmosphere. Cells were used at late postconfluence culture after $21 \mathrm{~d}$, with a change of medium every $2 \mathrm{~d}$. The monolayer was washed twice with $1 \mathrm{~mL}$ of PBS to remove traces of antibiotics, and $1 \mathrm{~mL}$ of Dulbecco's modified Eagle's medium without antibiotics was added to each well. The plates were incubated for $1 \mathrm{~h}$ at $37^{\circ} \mathrm{C}$ before the adherence assay.

Lactobacillus acidophilus cultures were grown at $37^{\circ} \mathrm{C}$ until pH 6.0 in $15 \mathrm{~mL}$ of either MRS or SM, inoculated with $750 \mu \mathrm{L}$ of an overnight culture. To study the influence of the growth medium on adhesion of $L$. acidophilus NCFM, cultures in MRS or SM were centrifuged at $3,220 \times g$ for $10 \mathrm{~min}$, and the pellets were washed once with an equal volume of phosphate buffer ( $\mathrm{pH}$ 6.0) and resuspended either in phosphate buffer ( $\mathrm{pH}$ 6.0) or SM acidified to $\mathrm{pH} 6.0$ with lactic acid. Initial cell counts per milliliter were determined in both samples to ensure comparable counts between samples to be used in adherence assays. To compare the adhesion ability of selected L. acidophilus mutant strains (listed in Table 1), cultures were grown in SM until reaching $\mathrm{pH}$ 6.0, and then the cells were removed, resuspended, counted, and used directly in adhesion assays.

One milliliter of each sample was added to each well of the tissue culture plate and incubated at $37^{\circ} \mathrm{C}$ for 1 h. Monolayers were washed 5 times with $1 \mathrm{~mL}$ of PBS and cells were desorbed by addition of $1 \mathrm{~mL}$ of $0.05 \%$ Triton-X100. The number of viable adhering bacteria was determined by plating serial dilutions on MRS agar plates. Three wells per sample were used and each adherence assay was conducted in triplicate. Bacterial adhesion was expressed as a percentage of the control strain.

\section{RESULTS AND DISCUSSION}

\section{Growth and Acidification Activity}

To determine the optimal culture conditions for preparation of cells for the microarray studies, the growth and acidification of L. acidophilus NCFM $37^{\circ} \mathrm{C}$ in MRS and $11 \%$ skim milk (SM) was examined, in triplicate (Supplementary Figure 1 available online: http://jds. fass.org/content/vol92/issue3/). The maximum specific growth rate $\left(\boldsymbol{\mu}_{\max }\right)$ of $L$. acidophilus in SM was less than half of the $\mu_{\max }$ of the strain growing in MRS (0.17 and 0.47 per $\mathrm{h}$, respectively). The acidification rate of L. acidophilus in MRS and SM was evaluated by continuous measurement of $\mathrm{pH}$. No differences in acidification rates were observed between MRS and SM during the first $3 \mathrm{~h}$ of incubation, each decreasing the $\mathrm{pH} 0.05$ units per h). At $9 \mathrm{~h}$, L. acidophilus NCFM decreased the culture $\mathrm{pH}$ by 0.14 and 0.055 units per $\mathrm{h}$ for MRS and SM, respectively.

\section{Gene Expression Profile of L. acidophilus During Growth in Milk}

A loop experimental design was employed in a time course experiment to monitor the transcriptional response of L. acidophilus NCFM during growth in SM. We obtained RNA at times $5 \min (\mathrm{pH}=6.4 ; \approx 2.1 \times$ $\left.10^{7} \mathrm{cfu} / \mathrm{mL}\right), 4 \mathrm{~h}\left(\mathrm{pH}=5.8 ; \approx 3.8 \times 10^{7} \mathrm{cfu} / \mathrm{mL}\right), 8$ $\mathrm{h}\left(\mathrm{pH}=5.4 ; \approx 7.1 \times 10^{7} \mathrm{cfu} / \mathrm{mL}\right)$, and $12 \mathrm{~h}(\mathrm{pH}=$ $4.9 ; \approx 1.5 \times 10^{8} \mathrm{cfu} / \mathrm{mL}$; see Supplementary Figure 1 available online: http://jds.fass.org/content/vol92/ issue $3 /)$ and the RNA was compared in an unbalanced loop-design. The statistical filter $[-\log 10(P$-values $)<$ -1.98] allowed 791 genes to pass, with 398 that were differentially expressed between paired time points in at least one time point, representing $21 \%$ of $1,864 \mathrm{ORF}$ in the complete genome of L. acidophilus.

A clusters of orthologous groups (COG) classification of differentially expressed genes during growth in SM (Figure 1) indicated that the majority of genes induced at $4 \mathrm{~h}$ belonged to the translation, ribosomal structure and biogenesis $[\mathrm{J}]$ category, whereas most of the underexpressed genes belonged to carbohydrate transport and metabolism $[\mathrm{G}]$. At $8 \mathrm{~h}$, amino acid transport and metabolism $[\mathrm{E}]$ and $[\mathrm{J}]$ were the most up-regulated categories, and the majority of down-regulated genes were either unknown or could not be included in any COG category. Interestingly, at $12 \mathrm{~h}$ most of up-regulated genes were in an unknown/no GOG category, followed by genes included in the categories $[\mathrm{E}],[\mathrm{J}]$, and cell wall, membrane, envelope biogenesis $[\mathrm{M}]$. Again, the majority of genes down-regulated was in the unknown/ no GOG category or included in $[\mathrm{G}]$. However, the third most represented category was replication, recombination and repair $[\mathrm{L}]$.

\section{Expression of Genes of the Proteolytic Enzyme System}

The proteolytic systems of $\mathrm{LAB}$ are divided in 3 functional categories: (i) proteinases, which degrade caseins into small peptides; (ii) transport systems, which import peptides and amino acids; and (iii) cytoplasmic peptidases (Savijoki et al., 2006; Table 2). A step-down quadratic regression analysis (Liu et al., 2005) was applied to statistically significant genes to identify bio- 


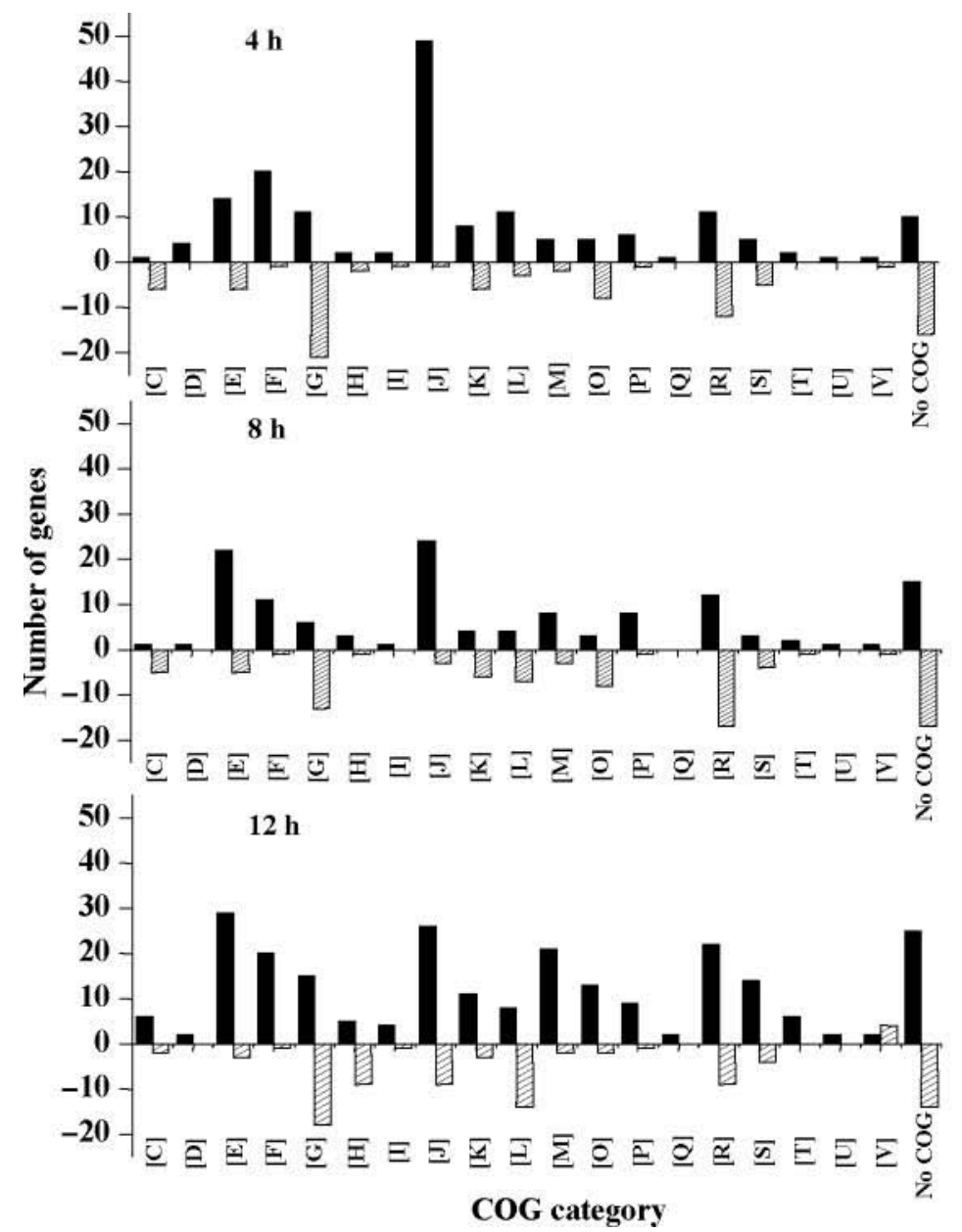

[C] Energy production and conversion

[D] Cell cycle control, cell division, chromosome partitioning

[E] Amino acid transport and metabolism

[F] Nucleotide transport and metabolism

[G] Carbohydrate transport and metabolism

$[\mathrm{H}]$ Coenzyme transport and metabolism

[I] Lipid transport and metabolism

[J] Translation, ribosomal structure and biogenesis

[K] Transcription

[L] Replication, recombination and repair

[M] Cell wall, membrane, envelope biogenesis

[O] Posttranslational modification, protein turnover, chaperones

[P] Inorganic ion transport and metabolism

[Q] Secondary metabolites biosynthesis, transport and catabolism

[R] General function prediction only

[S] Function unknown

[T] Signal transduction mechanisms

[U] Intracellular trafficking, secretion, and vesicular transport

[V] Defense mechanisms

Figure 1. Temporal clusters of orthologous groups (COG; Tatusov et al., 1997) classification of differentially expressed genes at 4, 8, and 12 h. Genes were classified according to the main COG domain present in the potentially encoded protein sequence. The COG functional category codes are indicated on the right.

logically meaningful gene expression patterns. In this analysis, time is considered as a continuous variable. Figure 2 shows the temporal gene expression patterns obtained by this analysis for members of the proteolytic enzyme system. Patterns obtained included: Flat (not shown; no significant differential expression over time), linear up-regulated regression pattern $(\mathbf{L U})$, quadratic concave regulated regression pattern (QC), quadratic convex regulated regression pattern $(\mathbf{Q V})$, quadratic linear concave up-regulated regression pattern (QLCU), and quadratic linear convex up-regulated regression pattern (QLVU). Interestingly, no genes fit into the linear down, quadratic linear concave down, or quadratic linear convex down patterns suggesting the absence of down-regulation over time for the studied subset of genes.

Gene expression of both LBA1512 (prtP), encoding a

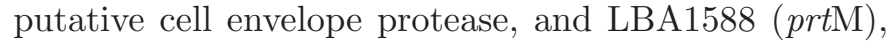
encoding a protease maturase protein, increased over time during growth of L. acidophilus in skim milk. Ex-

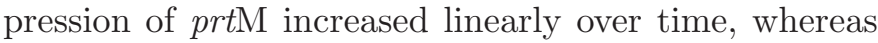
expression of prtP started to decrease at early stationary growth phase, probably coinciding with reduced levels of casein and low pH. The gene LBA1512 (prtP) encodes a putative precursor protein of 1,627 amino acids with a deduced molecular mass of $177.5 \mathrm{kDa}$ that shows significant amino acid sequence similarity from residues 189 to 961 (44\% identity and 58\% similarity) to the PR (catalytic) and A (function unknown) domains of PrtR, the cell wall-bound extracellular proteinase encoded by prt $\mathrm{R}$ in Lactobacillus rhamnosus (Pastar et al., 2003). Additional aa sequence similarity is found from residues 1217 to 1442 (32\% identity and 47\% similarity), the region of the protein that partially contains the B (cell envelope protease activity/specificity) and W (cell wall spacer) domains.

Previously conducted computer simulation analysis of predicted transporters in the L. acidophilus genome 
Table 2. Functional components of the proteolytic system of Lactobacillus acidophilus NCFM $^{1}$

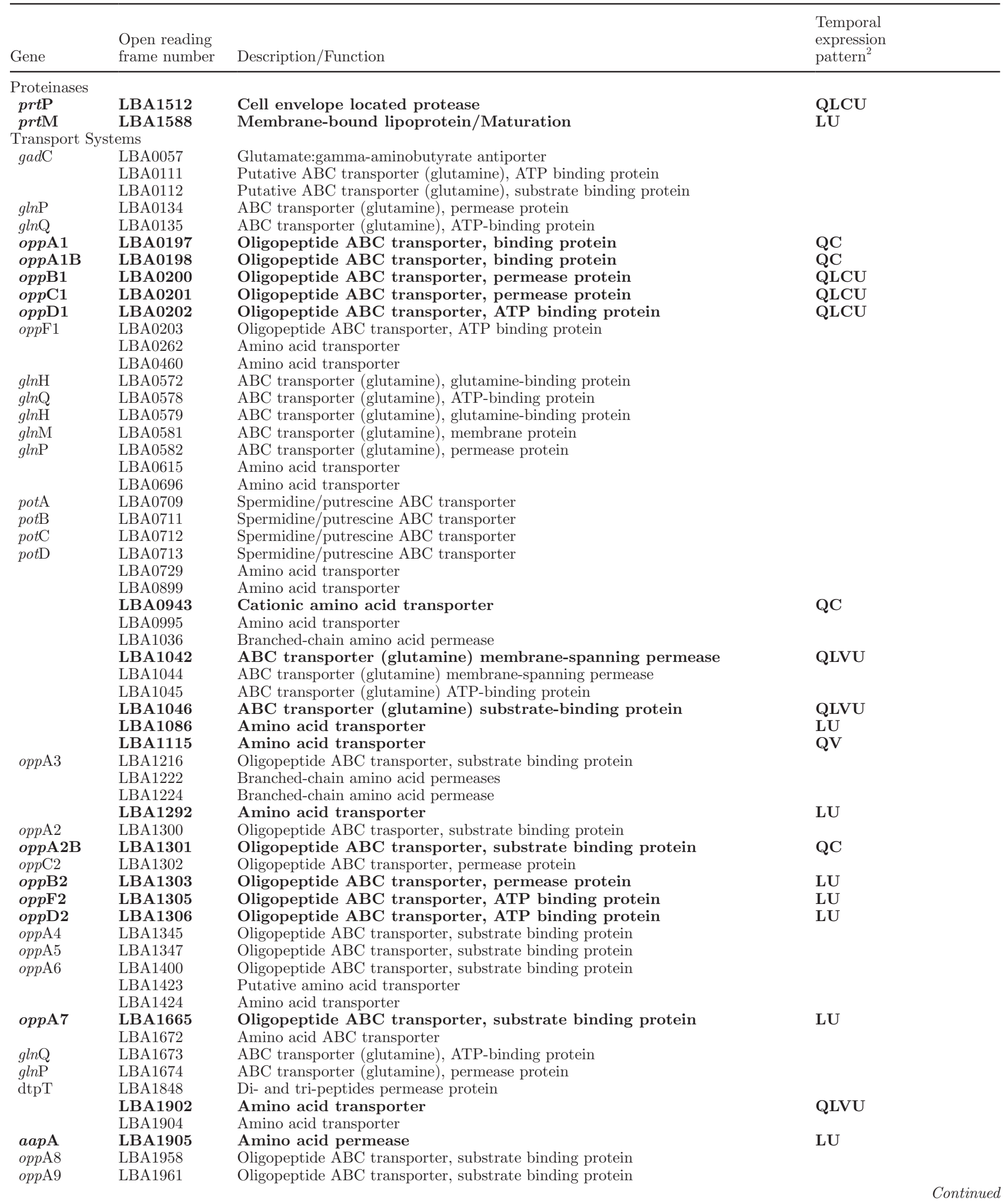


Table 2 (Continued). Functional components of the proteolytic system of Lactobacillus acidophilus NCFM $^{1}$

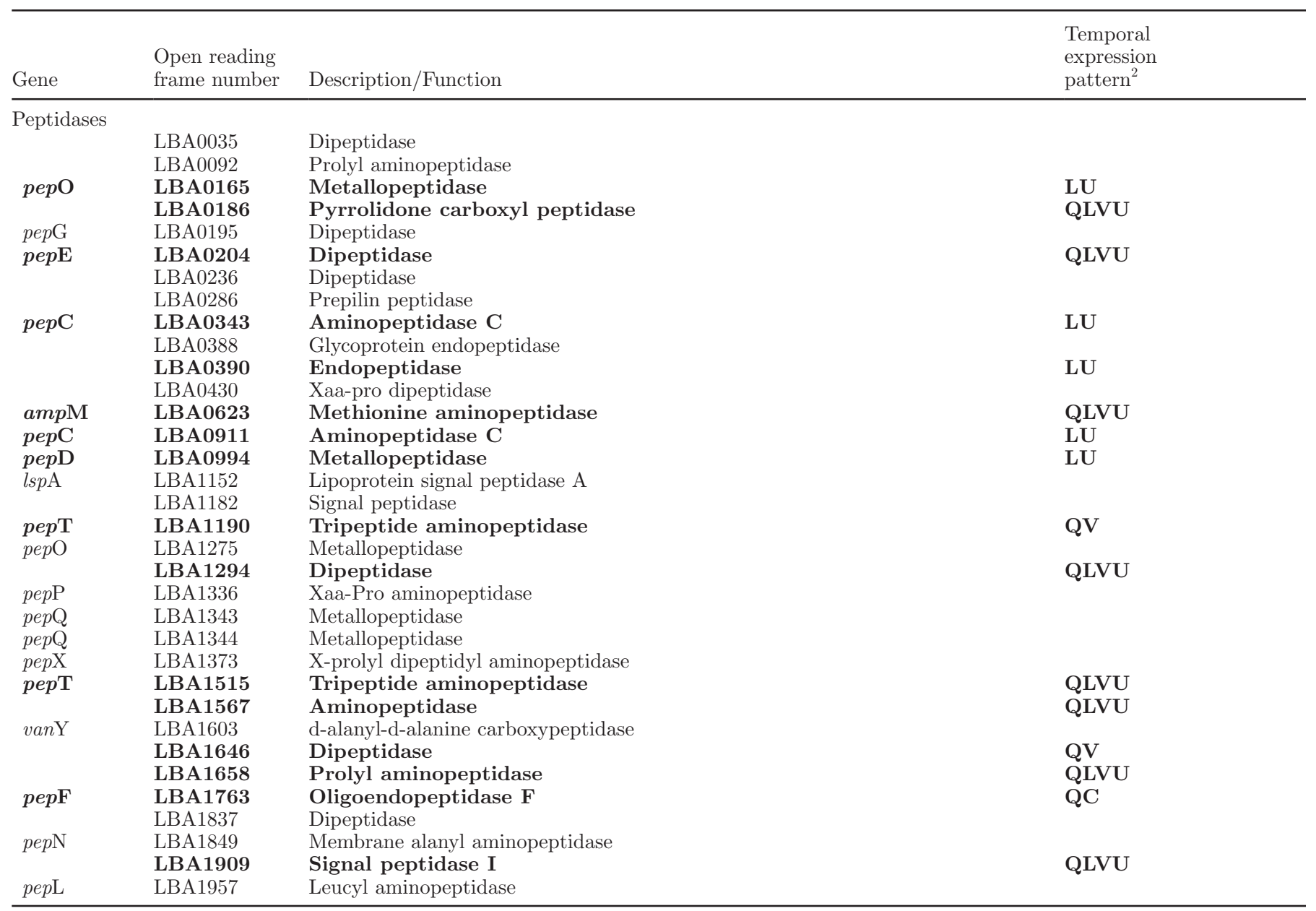

${ }^{1}$ Genes differentially expressed during growth in $11 \%$ skim milk are in boldface.

${ }^{2} \mathrm{LU}=$ linear upregulated regression pattern; $\mathrm{QC}=$ quadratic concave regulated regression pattern; QLCU = quadratic linear concave upregulated regression pattern; QLVU = quadratic linear convex upregulated regression pattern; QV = quadratic convex regulated regression pattern.

revealed the presence of 2 complete oligopeptide $\mathrm{ABC}$ transporters (Altermann et al., 2005; Azcarate-Peril et al., 2005): Opp1 (ORF LBA0197 to LBA0203) and Opp2 (ORF LBA1300 to LBA1306). Each consists of 6 genes coding for 2 ATP-binding proteins (OppD and $\mathrm{OppF}$ ), 2 membrane proteins (OppB and OppC), and 2 substrate-binding proteins (OppA and OppAB). Expression of Opp1 fell into the QLCU temporal expression pattern. In fact, Opp1 reached its maximum expression level at $4 \mathrm{~h}$. Expression of Opp2 increased over time falling into the LU pattern (Figure 3). These results suggest that Opp1 and Opp2 might have different specificities. In addition to the 4 periplasmic substratebinding proteins (OppA) encoded within Opp operons, 6 additional putative opp A genes were identified in $L$. acidophilus (LBA1216, LBA1347, LBA1400, LBA1665, LBA1958, and LBA1961). Only 4 oppA genes were differentially expressed over time: LBA0197, LBA0198 (adjacent to Opp1), and LBA1301 (adjacent to Opp2) fell in the QC regression pattern, and LBA1665 was included in the LU pattern.

According to its genome sequence, L. acidophilus has a restricted capacity to synthesize amino acids (Altermann et al., 2005). Lactobacillus acidophilus NCFM has the potential to synthesize cysteine, serine, and aspartate de novo. Additionally, cysteine and serine could be synthesized from pyruvate, and aspartate from fumarate. Based on these 3 amino acids, a series of other derivatives might be generated (asparagine, threonine, glycine, lysine, methionine, glutamine, and glutamate). Because neither de novo nor conversion pathways could be predicted for the remaining 13 amino acids, amino acid requirements must be satisfied by the uptake of amino acids and oligopeptides. Expression of several predicted amino acid transporters was also increased during growth in SM (Table 2), including a cationic 

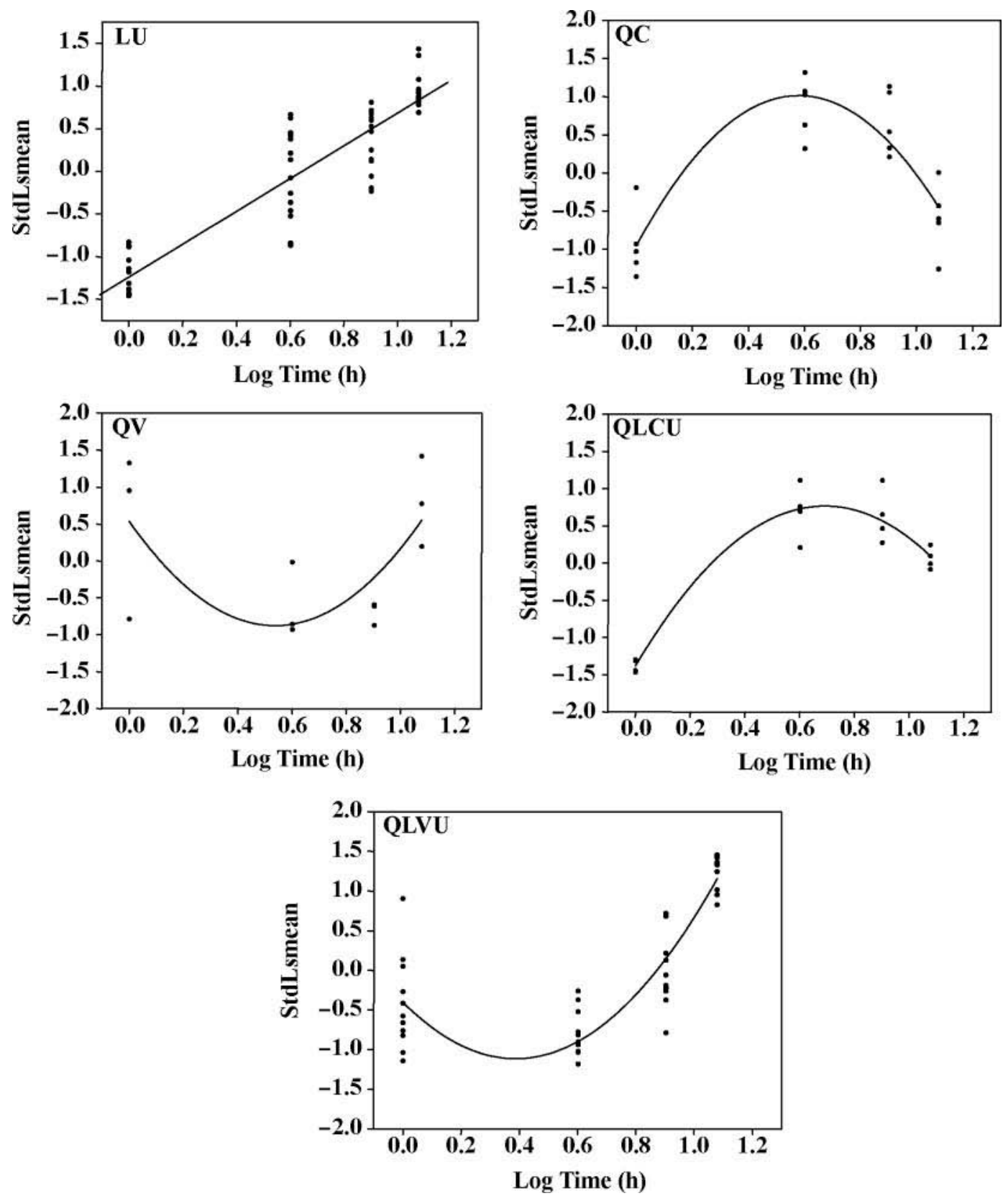

Figure 2. Temporal expression patterns of genes of the proteolytic system identified by the quadratic regression method (Liu et al., 2005). Patterns obtained included: Flat (not shown; no significant differential expression over time), linear up-regulated regression pattern (LU), quadratic concave regulated regression pattern (QC), quadratic convex regulated regression pattern (QV), quadratic linear concave up-regulated regression pattern (QLCU), and quadratic linear convex up-regulated regression pattern (QLVU).

amino acid transporter and members of the glutamine ABC transporter operon. Additionally, 16 peptidases were differentially expressed over time. Expression of 5 peptidases increased over time in an LU pattern.

\section{Expression of Carbohydrate Utilization Genes}

Lactose is the principal carbohydrate in the milks of all mammals. Milk also contains trace amounts of other sugars, including glucose, fructose, glucosamine, galactosamine, neuraminic acid, and small amounts of oligosaccharides, with sialyllactose being the most represented in bovine milk (Kunz et al., 2000). Lactobacillus acidophilus NCFM can transport and utilize glucose, sucrose, fructose, trehalose, melibiose, gentiobiose, cellobiose, maltose, mannose, fructooligosaccharides, raffinose, lactose, galactose, amygdalin, salicin, arbutin, and N-acetyl-glucosamine (Altermann et al., 
Table 3. Ratios and patterns of expression of genes involved in stress and autoinducer-2-mediated quorum sensing

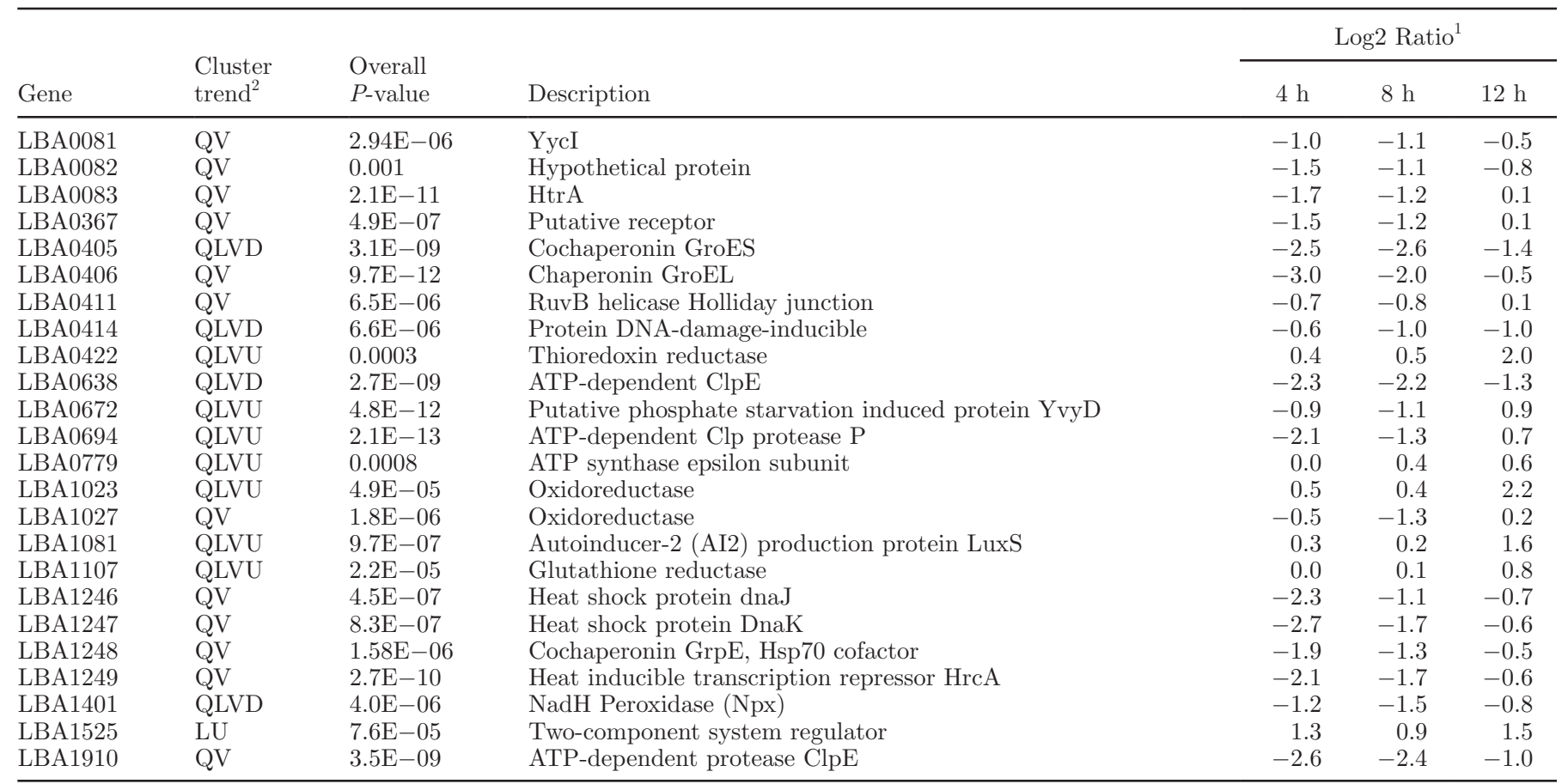

${ }^{1}$ Genes differentially expressed $(>1.5$-fold; $-\log 10(P$-values $)<-1.98)$ compared with time $0 \mathrm{~h}$.

${ }^{2} \mathrm{LU}=$ linear up-regulated regression pattern; QLVD = quadratic linear convex down; QLVU = quadratic linear convex up-regulated regression pattern; $\mathrm{QV}=$ quadratic convex regulated regression pattern.

2005; Barrangou et al., 2006). Several sugar transporters were differentially expressed in L. acidophilus growing in SM. Among the phosphotransferase transport systems, a lactose-specific transporter (LBA0989) was overexpressed at $12 \mathrm{~h}, 2$ cellobiose-specific transporters (LBA0491 and LBA0606) were overexpressed at 4 $\mathrm{h}$, and an arbutin-specific transporter was repressed at times 4 and $12 \mathrm{~h}$. The $\mathrm{ABC}$ transporters responsible for the uptake of maltose (LBA1865-LBA1866), lactose/galactose (LBA1463) and one uncharacterized sugar transporter (LBA0045) were highly expressed at $5 \mathrm{~min}$ and under expressed at times 4,8 , and 12 h. Interestingly, an uncharacterized sugar transport system encoded by LBA1944 to LBA1946 was induced mainly during logarithmic growth phase, at $8 \mathrm{~h}$. The genes/systems involved in carbohydrate utilization differentially expressed upon exposure to milk included lactose/galactose, fructose, maltose and N-acetylglucosamine. In contrast with the expression patterns of genes involved in proteolysis, expression of genes involved in lactose utilization were increased at time 5 min, suggesting that this region is rapidly induced upon exposure of L. acidophilus to the dairy environment, especially when cultures have previously been transferred in SM. The same pattern was observed for genes involved in maltose and fructose utilization. On the other hand, N-acetylglucosamine-6-P deacetylase (LBA0144) and glucosamine-6-phosphate isomerase (LBA1948), involved in the utilization of glucosamine, were among the highest genes induced at $4 \mathrm{~h}$. In fact, microarray data indicated that $L$. acidophilus uses the glucosamine-6-phosphate isomerase (LBA1948; EC 3.5.99.6) and not the D-fructose-6-phosphate amidotransferase (LBA0462; EC 2.6.1.16) to process glucosamine 6-phosphate generating fructose 6-phosphate (and ammonia).

Components of the general carbohydrate utilization regulon were differentially expressed in L. acidophilus during growth in milk; specifically, pts $\mathrm{H}(\mathrm{HPr}$, LBA0639) ptsI (EI, LBA0640), and ccpA (CcpA, LBA0431) showed an LU trend indicating increased expression over time

\section{Stress, Quorum Sensing, and 2-Component Regulatory Systems}

Step-down quadratic regression analysis (Liu et al., 2005) applied to statistically significant genes for pattern recognition indicated that 24 genes, potentially involved in the stress response of L. acidophilus, showed biologically meaningful temporal expression patterns (Table 3). Interestingly the gene responsible for the 
generation of the autoinducer-2 (AI2) molecule, which mediates cell-density responses, followed a QLVU pattern of expression. The genome sequence of L. acidophilus NCFM contains the complete pathway for the production of AI2 (Buck et al., 2008); however, only luxS (LBA1081) was differentially expressed.

Of nine 2-component regulatory systems (2CRS) encoded by L. acidophilus, only 2 showed high levels of expression and were differentially expressed. The transcriptional regulator $1525 \mathrm{RR}$, involved in the regulation of acid resistance and proteolytic activity in L. acidophilus (Azcarate-Peril et al., 2005) showed a linear up trend of expression in milk, mirroring the expression of the oligopeptide transport systems (Figure 3). In addition, the 2CRS similar to the one encoded by the $y y c \mathrm{~F}$ and yycG genes in Bacillus subtilis (Fabret and Hoch, 1998) showed a quadratic convex regulated regression pattern, with high levels of expression at 5 min and 12 h. In this organism, as well as in L. acidophilus NCFM, the $2 \mathrm{CRS}$ is part of an operon containing 3 genes with no known function and a gene coding for an HtrA-like protease. In B. subtilis, this operon was transcribed during growth, and its transcription decreased as the cells approached stationary phase. Most of the stress-related genes differentially expressed showed either a QV or a QLVU pattern, suggesting high levels of expression toward stationary phase.

\section{Expression of Adhesion Genes in SM}

Adhesion to the intestinal mucosa is considered an important trait for bacterial retention in the gastrointestinal tract and interaction with immunomodulatory cells of the mucosal immune system. Consequently, the capacity to adhere to the intestinal mucosa is a very important selection criterion for probiotics (Tuomola et al., 2001). The genome sequence of $L$. acidophilus indicated the presence of several genes encoding putative adhesion factors (Altermann et al., 2005), and some of these have already been shown to play a role in adherence to Caco-2 epithelial cells, in vitro (Buck et al., 2005). Genes putatively involved in adhesion, containing a cell wall anchoring motif LPxTG or with similarities to previously characterized adhesion genes, differentially expressed during growth of L. acidophilus in SM are listed in Table 4. Eight genes encoding proteins containing the LPxTG and/or LPQTxE motif were differentially expressed; however, only 3 of them (2 mub genes, LBA1392 and LBA1652, and thrS) showed recognizable patterns of expression over time. Expression of ORF LBA0493 and LBA1850, encoding putative aggregation-promoting proteins, increased over time falling into QLCU and QLVU temporal patterns, respectively. LBA0493 was one of the most induced

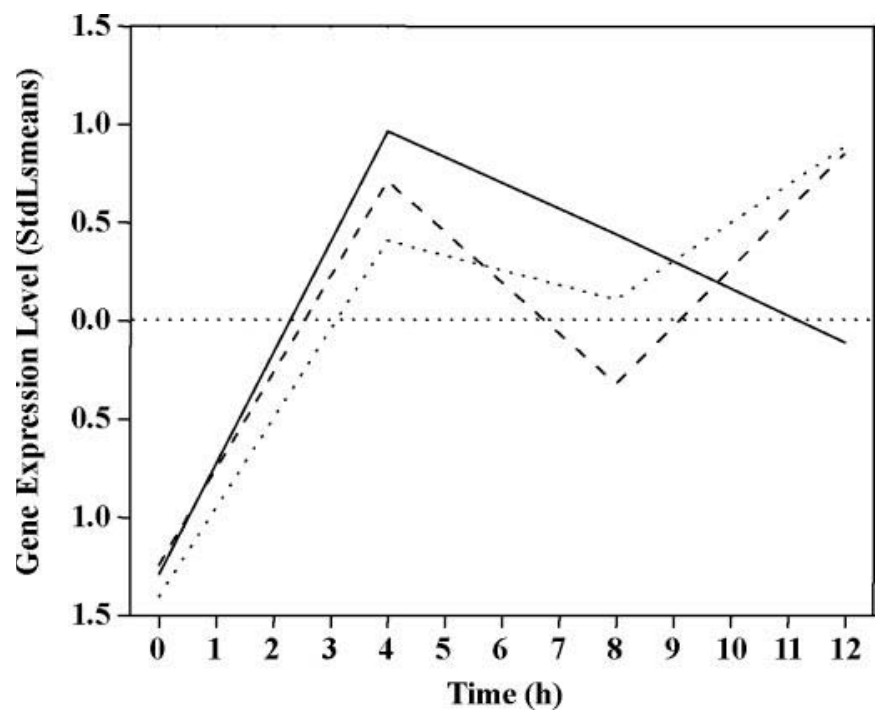

Figure 3. Mean gene expression of oligopeptide transport 1 (opp1, continuous line), opp2 (dashed line), and LBA1524HPK-LBA1525RR 2-component regulatory system (dotted line) over time during growth of $L$. acidophilus NCFM in milk.

genes over time [up to 5.6 -fold (2.5-fold in $\log 2$ scale) at $4 \mathrm{~h}$.

\section{Growth and Survival of Selected Mutant Strains in Milk and Acidified Milk}

Microarray analysis allowed us to identify genes that were differentially expressed during growth of L. acidophilus in reconstituted $11 \% \mathrm{SM}$. To further examine for any relationships between milk, growth, and potential probiotic properties we selected $14 \mathrm{~L}$. acidophilus mutant strains present in our culture collection (Table 1), that were inactivated for genes that were differentially expressed in milk.

The method described by Fonseca et al. (2000) was used to correlate acidification rates with the initial cell concentration to determine if any of the inactivated genes were involved in acidification activity and, hence, growth of L. acidophilus in milk (Table 5). Four mutant strains showed significantly $(P<0.1)$ different $t m$ values than their respective control strain. As expected, the histidine protein kinase (LBA1524HPK) mutant previously characterized as involved in the regulation of genes involved with acid resistance and proteolysis showed an increased $t m$ value in SM (Azcarate-Peril et al., 2005). The other mutant strains showing significantly different $t m$ values were $c d p \mathrm{~A}$ (Altermann et al., 2004), mucin-binding protein (LBA1392; Buck et al., 2005), and an uncharacterized putative myosin crossreactive antigen (LBA0555; A. Dobson, North Carolina State University; unpublished results). 
Table 4. Cell wall anchoring proteins (LPxTG and LPQTxE motifs) and putative adhesion factors in L. acidophilus NCFM (modified from Altermann et al., 2005) ${ }^{1}$

\begin{tabular}{|c|c|c|c|c|}
\hline Gene & Open reading form designation & Motif type & COG category & $\begin{array}{l}\text { Temporal } \\
\text { expression pattern }\end{array}$ \\
\hline LBA0036 & Conserved hypothetical & LPxTG & [D] COG1196 Chromosome segregation ATPases & Not significant \\
\hline LBA0493 & Aggregation promoting protein & & SP0107 & QLCU \\
\hline LBA0514 & Surface layer protein & & [M] Cell wall_membrane_envelope biogenesis & QV \\
\hline LBA0530 & Conserved hypothetical & LPxTG & [R] COG4851: prot. involved in sex pheromone biosynthesis & Not significant \\
\hline LBA0701 & Unknown & LPxTG & {$[\mathrm{M}]$ COG4932 Predicted outer membrane protein } & Flat \\
\hline LBA0782 & RodA & LPxTG & [D] COG0772: Bacterial cell division membrane protein & Flat \\
\hline LBA0833 & FtsW & LPxTG & D] COG0772: Bacterial cell division membrane protein & Not significant \\
\hline LBA0919 & Conserved hypothetical & LPxTG & [S] Function unknown & Not significant \\
\hline LBA0927 & Membrane protein & LPxTG & [S] Function unknown & Flat \\
\hline LBA1018 & Mub & LPxTG & SA1552 & Not significant \\
\hline LBA1019 & Mub & LPxTG, LPQTxE & [U]COG3210: Large prot. involved in heme utilization or adhesion & Not significant \\
\hline LBA1148 & FbpA & & [K] COG1293 Predicted RNA-binding protein & Flat \\
\hline LBA1155 & Conserved hypothetical & LPxTG & [L] COG0116: Predicted N6-adenine-specific DNA methylase & Not significant \\
\hline LBA1244 & Sortase & & [M] COG3764 Sortase & Flat \\
\hline LBA1287 & tRNA Methyltransferase & LPxTG & [J] COG0336 tRNA-(guanine-N1)-methyltransferase & Flat \\
\hline LBA1377 & Mucus binding protein precursor & LPxTG & [U] COG3210: Large prot. involved in heme utilization or adhesion & Not significant \\
\hline LBA1392 & Mub & LPxTG & L39650 & LD \\
\hline LBA1496 & Fibrinogen-binding protein & LPxTG, LPQTxE & [U] COG3210: Large prot. involved in heme utilization or adhesion & Not significant \\
\hline LBA1543 & ThrS & LPxTG & [J] COG0441: Threonyl-tRNA synthetase & QLVU \\
\hline LBA1611 & FmtB & LPxTG & SA126 & Not significant \\
\hline LBA1633 & Surface protein & LPxTG, LPQTxE & MYPU_5250 & Flat \\
\hline LBA1634 & Surface protein & LPxTG & SA0520 & Not significant \\
\hline LBA1652 & Mub & LPxTG & L39650 & $\mathrm{QC}$ \\
\hline LBA1654 & PspC & LPxTG & [U] COG3210: Large prot. involved in heme utilization or adhesion & Not significant \\
\hline LBA1690 & Putative surface exclusion protein & & SPy0269 & QLVU \\
\hline LBA1740 & Putative membrane protein & LPxTG, LPQTxE & lin0803 & Not significant \\
\hline LBA1793 & Conserved hypothetical & LPxTG & YDR $439 \mathrm{w}$ & Not significant \\
\hline LBA1850 & Aggregation promoting protein & & SP0107 & QLVU \\
\hline
\end{tabular}

${ }^{1}$ Significantly differentially expressed genes during growth in $11 \%$ skim milk and their temporal expression pattern are in boldface.

$\stackrel{\text { }}{\stackrel{2}{\Sigma}} \quad{ }^{2}$ Flat $=$ no significant differential expression over time; LD = linear down; QC = quadratic concave regulated regression pattern; QLCU = quadratic linear concave up-regulated 
Table 5. Acidification activity of Lactobacillus acidophilus strains in $11 \%$ skim milk $^{1}$

\begin{tabular}{|c|c|c|c|c|c|c|}
\hline NCK number & Strain & $\mathrm{pH}(16 \mathrm{~h})$ & \multicolumn{4}{|c|}{ Acidification parameter ${ }^{2}$} \\
\hline NCK0056 $6^{3}$ & NCFM, wt & $4.2( \pm 0.01)$ & $1.2( \pm 0.4) \times 10^{7}$ & $400.0( \pm 2.0)$ & $-9.2( \pm 0.7)$ & $249.4( \pm 14.5)$ \\
\hline NCK $1398^{5}$ & NCFM::lacL & $6.1( \pm 0.2)$ & $1.5( \pm 0.2) \times 10^{7}$ & $381.7( \pm 3.7)$ & $-0.5( \pm 0.03)$ & $373.4( \pm 4.1)^{*}$ \\
\hline NCK1375 & NCFM $:: c d p \mathrm{~A}$ & $4.6( \pm 0.2)$ & $0.6( \pm 0.2) \times 10^{7}$ & $400.3( \pm 13.9)$ & $-6.9( \pm 0.8)$ & $294.2( \pm 9.0)^{*}$ \\
\hline NCK1376 & NCFM::cfa & $4.2( \pm 0.1)$ & $1.0( \pm 0.4) \times 10^{7}$ & $396.4( \pm 3.2)$ & $-8.6( \pm 0.4)$ & $258.0( \pm 4.3)$ \\
\hline NCK1661 & NCFM::fbpA & $4.4( \pm 0.02)$ & $1.5( \pm 0.8) \times 10^{7}$ & $396.0( \pm 4.3)$ & $-7.7( \pm 0.8)$ & $269.0( \pm 7.2)$ \\
\hline NCK1662 & NCFM::R28 & $4.2( \pm 0.2)$ & $1.4( \pm 0.7) \times 10^{7}$ & $396.6( \pm 3.0)$ & $-7.9( \pm 1.0)$ & $267.9( \pm 11.2)$ \\
\hline NCK1686 & NCFM::1524HPK & $5.4( \pm 0.1)$ & $2.2( \pm 0.5) \times 10^{7}$ & $391.3( \pm 4.4)$ & $-4.0( \pm 0.3)$ & $323.9( \pm 4.2)^{*}$ \\
\hline NCK1728 & $\mathrm{NCFM} \Delta f r c$ & $4.3( \pm 0.1)$ & $1.5( \pm 0.2) \times 10^{7}$ & $400.7( \pm 2.5)$ & $-9.6( \pm 0.3)$ & $242.1( \pm 2.6)$ \\
\hline NCK1730 & NCFM::LBA0555 & $4.5( \pm 0.1)$ & $1.3( \pm 0.6) \times 10^{7}$ & $400.9( \pm 10.4)$ & $-7.2( \pm 0.8)$ & $282.9( \pm 1.1)^{*}$ \\
\hline NCK1746 & NCFM:: $m d o B$ & $4.6( \pm 0.2)$ & $2.0( \pm 0.3) \times 10^{7}$ & $439.9( \pm 5.0)$ & $-10.1( \pm 0.4)$ & $269.7( \pm 12.1)$ \\
\hline
\end{tabular}

*Asterisks indicate $t m$ significantly different $(P<0.1)$ from the corresponding control strain.

${ }^{1}$ Each value represents the mean of 4 independent experiments. Standard deviations are indicated in parentheses.

${ }^{2} x_{0}=$ initial bacterial concentration; $a$ and $b=$ equation parameters for each strain; $t m=$ time in minutes necessary to reach the maximum acidification rate in milk (Fonseca et al., 2000).

${ }^{3}$ Used as a reference strain and control for NCK1728.

${ }^{4}$ Used as a control for the knockout strains.

${ }^{5}$ Negative control (lactose negative strain).

To evaluate the effect of the inactivated genes on cell survival under conditions emulating yogurt storage, L. acidophilus NCFM (wild type), NCK1376 (NCFM::cfa; used as $\mathrm{Em}^{\mathrm{R}}$ control), $\mathrm{NCK1398}$ (NCFM::lacL), NCK1660 (NCFM::mub), NCK1686 (NCFM::LBA1524HPK), NCK1730(NCFM::LBA0555), and NCK1822 (NCFM::LBA1690) were held at $4^{\circ} \mathrm{C}$ over a 2-week period in SM acidified at $\mathrm{pH} 4.5$ with lactic acid (Table 6). All the selected mutant strains showed a $>2$-fold reduction in survival rates after a 14-d period compared with the control. Mutants containing the $1524 \mathrm{HPK}$, lacL, and mub inactivated genes showed increased death rates $(\boldsymbol{K}$, per h) suggesting that the inactivated genes have a role in survival during storage at $4^{\circ} \mathrm{C}$ in acidified SM. A strong correlation was observed between $t m$ and $K$ values for all the studied strains, indicating that strains showing high $t m$ values and, consequently, lower acidification activities are also less able to survive at low $\mathrm{pH}$ and $4^{\circ} \mathrm{C}$ (Figure 4).

\section{Effect of Milk on Adhesion of L. acidophilus Strains to Mucin and Caco-2 Cells}

To determine the overall effect of SM on the adhesion capability of selected $L$. acidophilus strains, we examined the effect of SM as a growth medium and as a suspension-adhesion medium on the ability of $L$. acidophilus NCFM to adhere to Caco-2 cells. Lactobacillus

Table 6. Survival of selected L. acidophilus strains in acidified skim milk (pH 4.5 adjusted with lactic acid) at $4^{\circ} \mathrm{C}$ over a 14 -d period

\begin{tabular}{llcccc}
\hline & & \multicolumn{2}{c}{$\%$ survival after } & & \\
\cline { 3 - 4 } Strain & Genotype & $6 \mathrm{~d}$ & $14 \mathrm{~d}$ & $K\left(\mathrm{~h}^{-1}\right)$ & $\mathrm{R}$ \\
\hline NCFM & Wild-type & 45 & 8 & -0.06 & -0.99 \\
NCK1376 & NCFM::LBA1274 cfa & 33 & 3 & $\mathrm{ND}^{2}$ & ND \\
NCK1398 & NCFM::LBA1398 lacL & 7 & 0 & -0.22 & -0.99 \\
NCK1660 & NCFM::LBA1392 mub & 11 & 0.5 & -0.11 & -0.95 \\
NCK1686 & NCFM::LBA1524 hpk & 10 & 0.01 & -0.19 & -0.99 \\
NCK1730 & NCFM::LBA0555 & 19 & 0.7 & -0.08 & -0.90 \\
NCK1822 & NCFM::LBA1690 & 21 & 0.1 & -0.06 & -0.93 \\
\hline
\end{tabular}

${ }^{1} \mathrm{Em}^{\mathrm{R}}$ control strain.

${ }^{2}$ Not determined. 


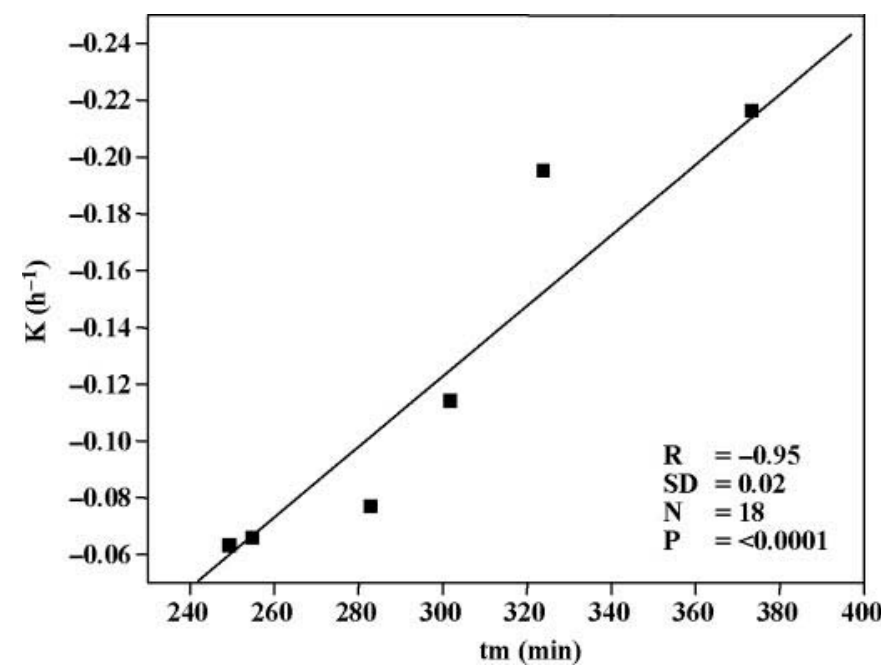

Figure 4. Correlation between $t m$ (time in minutes necessary to reach the maximum acidification rate in milk) and $K$ (death rate) values corresponding to acidification rates in milk and survival in acidified milk, respectively.

acidophilus NCFM was grown either in MRS or SM until $\mathrm{pH} 6.0$, after one wash with phosphate buffer $(\mathrm{pH}$ 6.0 ); cells were resuspended either in the same buffer or in $\mathrm{SM}$ at $\mathrm{pH} 6.0$ before exposure to Caco-2 cells. Resuspension of bacterial cells in SM after growth in MRS strongly reduced adhesive abilities of the bacterium (37\% adhesion loss). No significant differences in adhesion were observed when cell cultures were resuspended in phosphate buffer at $\mathrm{pH} 6.0$ or $\mathrm{SM}$ at $\mathrm{pH} 6.0$ after growth in SM, suggesting that the resuspension medium did not have an effect on the adhesion properties of cultures grown in SM. The adherence abilities of
L. acidophilus NCFM was not affected by the growth medium, because the levels of adherence of cells grown in SM or MRS and resuspended in phosphate buffer were similar (data not shown).

To identify potential associations between genes differentially expressed in SM and adhesion properties, we compared the ability of L. acidophilus NCFM versus 6 selected mutants (see Table 1) to adhere to mucin and to Caco2-tissue culture cells. Two mutant strains, NCK1686 (NCFM::LBA1524HPK) and NCK1822 (NCFM::LBA1690) showed a 30\% decrease in adhesion to Caco-2 cells (Figure 5), suggesting that these proteins may play a role in adhesion of $L$. acidophilus when grown in milk. On mucin, NCK1686 showed a $31 \%$ reduction and NCK1822 more than a $68 \%$ reduction in adhesion. None of the other mutant strains were affected in adhesion on the 2 models tested, indicating that the insertionally inactivated genes in these strains; that is, myosin-crossreactive antigen (LBA0555), mucus binding protein precursor (LBA1392), and the $\beta$-galactosidase large subunit (LBA1398), are not involved in adherence of $L$. acidophilus when grown in milk.

\section{Discussion}

The overall transcriptional response of $L$. acidophilus NCFM, a widely used probiotic strain, was examined during growth in reconstituted SM. Temporal overall gene expression profiles in milk indicated that the expression of genes involved in carbohydrate utilization were rapidly induced at early stages of growth and decreased over time. Decreased levels of expression of carbohydrate utilization genes coincided with trends

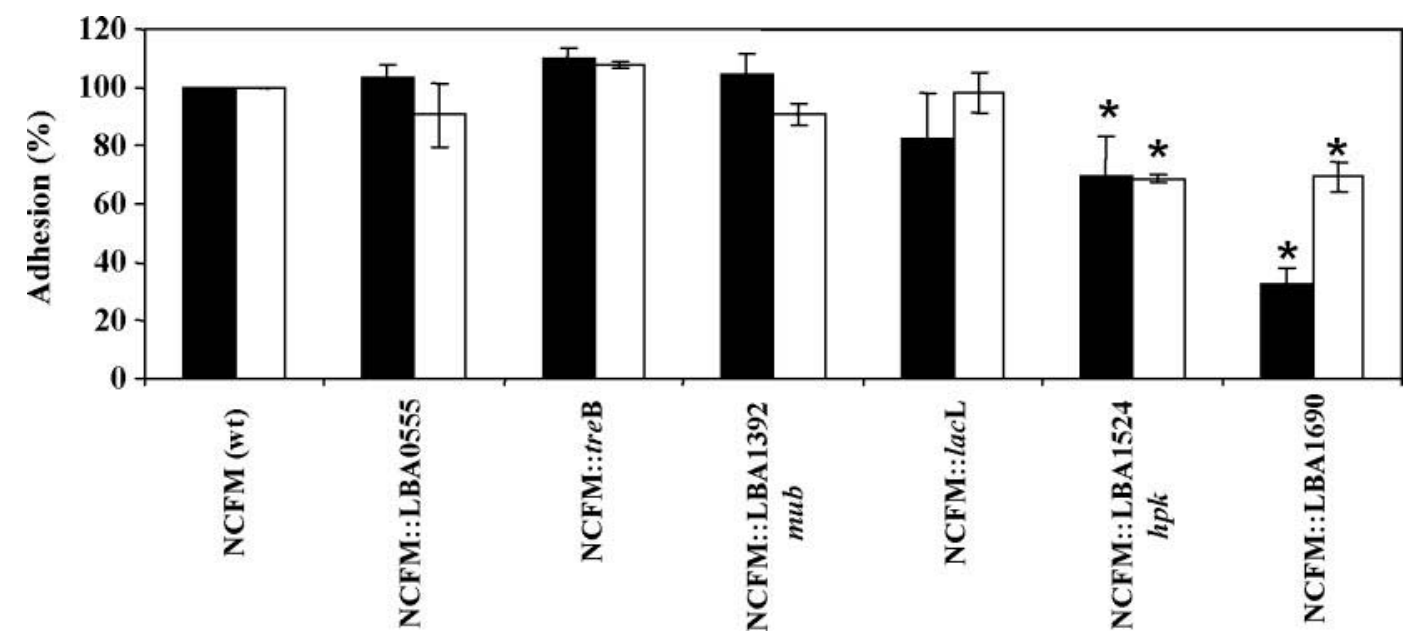

Figure 5. Adherence abilities of 6 L. acidophilus NCFM derivatives grown in skim milk, to mucin ( $\square$ ), and to Caco-2 cells ( $\square$ ). The results are expressed as a percentage of the wild-type strain. Values represent the mean of 3 independent experiments and error bars represent the standard deviation. The asterisks represent statistically significant $(P<0.05)$ differences between mutant and control strains. 
of increasing expression of key components involved in catabolite repression (ptsH, HPr, LBA0639; ptsI, EI, LBA0640; and $c с p A$, CcpA, LBA0431). The carbon catabolite repression (CCR) system controls the transcription of genes involved in the transport and catabolism of carbohydrates. The mechanism is widely distributed in bacteria (Gorke and Stulke, 2008), including lactic acid bacteria. In the model firmicute, the transcription factor CcpA (catabolite control protein A), HPr protein, and the bifunctional HPr kinase/ phosphorylase (HPrK) are the main players in CCR (Gorke and Stulke, 2008). Catabolite control protein $\mathrm{A}$ is one key component in the regulation of the sugar transport and utilization in LAB. Although some studies indicate a role as an activator, most of the published data indicate that CcpA acts as a repressor (reviewed by Titgemeyer and Hillen, 2002). Therefore, the overexpression of different sugar transport systems might be the reflection of gene derepression rather than induction of gene expression.

Conversely, proteolytic genes showed increasing patterns of expression over time. Interestingly, the 2 oligopeptide operons (opp 1 and opp2) encoded by $L$. acidophilus, which are involved in the transport of oligopeptides into the cell, showed different expression patterns. The maximum expression level of opp 1 was at $4 \mathrm{~h}$ (early logarithmic phase of growth), but the expression of opp 2 reached its maximum level at $12 \mathrm{~h}$ (early stationary phase). Expression of the 2-component regulatory LBA1524HPK-LBA1525RR in milk correlated with the expression of the oligopeptide transport systems as it showed increased levels of expression at 4 and $12 \mathrm{~h}$ (Figure 3). These results support previous data that indicated that LBA1524HPK-LBA1525RR was involved in regulation of gene expression of members of the proteolytic enzyme system (Azcarate-Peril et al., 2005). Studies of oligopeptide gene expression in lactobacilli are scarce. In L. delbrueckii ssp. bulgaricus no significant differences were detected in the amount of oligopeptide mRNA per total RNA in preparations from the early- and late-exponential phase cultures grown in whey broth culture (Peltoniemi et al., 2002). A recent study indicated that, in L. helveticus, growth in milk also significantly induced various peptidases, proteinases, and the oligopeptide transporters (Smeianov et al., 2007).

Sixteen peptidases showed noteworthy temporal patterns of expression in L. acidophilus. In contrast, only 9 peptidases were induced in L. helveticus (Smeianov et al., 2007) during growth in milk; however, in that study, gene expression was analyzed at one time point (9 h, pH 5.5) and not over the various growth phases. In L. acidophilus, only expression of oligoendopeptidase $\mathrm{F}$ ( $p e p \mathrm{~F}, \mathrm{LBA} 1763)$ peaked at $4 \mathrm{~h}$ displaying a $\mathrm{QC}$ pattern of gene expression because most of the differentially expressed peptidases were mainly expressed at $12 \mathrm{~h}$ (early stationary phase). The $p e p \mathrm{~F}$ gene is well conserved among lactobacilli, and other members of the LAB group. The $p e p \mathrm{~F}$ gene encoded by LBA1763 shows a $49 \%$ identity with pepF from Lactococcus lactis. In this bacterium, PepF hydrolyzes peptides containing more than 7 and less than 17 amino acids (Monnet et al., 1994). These expression profiles suggest an early role of PepF breaking larger peptides into smaller ones that will be then processed by other peptidases of the proteolytic system. Additionally, several aa transporters showed increased levels of transcription over time (Table 2). Interestingly, the differentially expressed genes LBA1115 and LBA1902 coding for aa transporters appear to be unique to the acidophilus group (including L. acidophilus, L. gasseri, and L. johnsonii) and L. reuteri.

Most of the stress-related genes differentially expressed showed either a QV or a QLVU pattern, suggesting high levels of expression toward stationary phase during growth of $L$. acidophilus in milk. These trends are in accordance with the accumulation of lactic acid (and consequent decrease in $\mathrm{pH}$ ) and other secondary metabolites. Several mutant strains were evaluated for their acidification activity, survival during storage conditions, and adhesive properties to mucin and Caco-2 cells. These derivatives contained mutations in genes found to be differentially expressed when L. acidophilus was grown in milk. As expected, the derivative with a mutation in lacL showed decreased acidification ability (as indicated by higher $t m$ values) and decreased survival in acidified skim milk at $4^{\circ} \mathrm{C}$, indicating that $\beta$-galactosidase activity is required not only for growth but also for survival under storage conditions. We observed increased $t m$ values and reduced survival in acidified milk at $4^{\circ} \mathrm{C}$ for strains carrying mutations in LBA1524HPK, LBA0555 (annotated as a myosincrossreactive antigen) and LBA1392, a mucus-binding protein precursor $(m u b)$ demonstrated to mediate adherence to intestinal epithelial cells (Buck et al., 2005).

Interestingly, lux S, responsible for the transformation of S-ribosylhomocysteine into homocysteine in the methyl activated cycle and the production of AI2 from methionine, showed similar trends of expression in milk as in MRS (Buck et al., 2008), with increased expression toward stationary phase. It is noteworthy that the luxis mutant strain showed increased $t m$ values (although not significant at a $P>0.1$ level) suggesting an important role for LuxS during growth in milk.

The adhesion capabilities of probiotic strains in the presence of milk have not been extensively analyzed. Ouwehand et al. (2001) reported reduced adhesion 
levels of $L$. brevis, $L$. reuteri, and L. rhamnosus upon exposure and growth in skim milk, in milk containing $1.5 \%$ fat, and in nonhomogenized milk with fat content of 1.6 to $1.9 \%$. In our study, we observed comparable levels of adhesion when $L$. acidophilus NCFM cells were grown in skim milk or MRS. This is a technologically relevant fact because probiotic cultures are often consumed via milk-based food products. Additionally, milk, through its buffering action, is likely to provide a protective medium to probiotics that will increase the number of microorganisms surviving the passage through the stomach to reach the small intestine. Some genes putatively involved in adhesion were expressed differentially during growth of L. acidophilus in milk. Especially relevant is the overexpression of the genes encoding aggregation-promoting proteins, specifically the protein encoded by LBA0493, which is similar to the aggregation-promoting factor (APF) described in L. crispatus M247 (Marcotte et al., 2004). It has been shown that a nonaggregating isogenic spontaneous mutant derived from M247 was unable to colonize the intestinal tract suggesting a role of aggregation in colonization of the gastrointestinal tract (Cesena et al., 2001).

In the present study, the comparison of adhesion abilities of 6 mutants indicated that an unknown membrane protein (LBA1690) was involved in adhesion of $L$. acidophilus NCFM grown in milk to mucin. Detectable differences were also observed for the HPK mutant and LBA1690 to Caco-2 cells. Some histidine protein kinases from $2 \mathrm{CRS}$ have already been shown to be involved in regulation of adherence of gram-positive pathogens such as Streptococcus agalactiae to immobilized fibrinogen via the regulation of the expression of bacterial cell surface components (Spellerberg et al., 2002), and adhesion of L. plantarum WCFS1 to a glass surface via the overexpression of genes involved in cell surface polysaccharides synthesis (Sturme et al., 2005). The specific role of LBA1524HPK-LBA1525RR in adhesion might be related to the function of the $2 \mathrm{CRS}$ in the regulation of the transport of oligopeptides (Azcarate-Peril et al., 2005) as it was demonstrated in $S$. gordonii and $S$. parasanguis, where a mutation of the oligopeptide permease systems led to a decrease in bacterial cell adhesion [reviewed by Leonard and Podbielski, (1999)]. However, it is not clear whether the oligopeptide-binding proteins can act as adhesins themselves or if they are required for the transport of signaling peptides that impact adherence factors.

The data available on the hypothetical protein LBA1690 revealed the presence of a signal peptide and a transmembrane domain, suggesting that this protein is secreted and anchored to the membrane. Further studies are needed to determine the function of this pro- tein and its potential role in adhesion. Surprisingly, the putative mucus-binding protein encoded by LBA1392, although differentially expressed during growth in milk, did not appear to have a role in adhesion during growth in milk, whereas this protein was previously shown to be involved in adherence on Caco- 2 cells after the strain was grown in MRS (Buck et al., 2005). It might be speculated that growth in milk alters the cell surface display to promote attachment in spite of the absence of the LBA1392: $m u b$ protein.

Our study presents, for the first time, the analysis of the effect of milk, as a delivery vehicle, on the global gene expression of a probiotic strain, L. acidophilus. Additionally, genes involved with growth and survival in milk have been identified, some of which may be potentially important for probiotic traits.

\section{ACKNOWLEDGMENTS}

This study was supported by the Southeast Dairy Foods Research Center; Dairy Management, Inc.; and the North Carolina Dairy Foundation. We thank J. Bruno-Barcena (Department of Microbiology, North Carolina State University) and E. Durmaz (Department of Food, Bioprocessing, and Nutrition Sciences, North Carolina State University) for scientific advice and helpful suggestions, and Jason Osborne, at the Department of Statistics (North Carolina State University), for his advice on microarray data analysis. We are grateful to the Genome Research Laboratory at North Carolina State University for technical assistance and staff that supported printing of the microarray slides.

\section{REFERENCES}

Altermann, E., L. B. Buck, R. Cano, and T. R. Klaenhammer. 2004. Identification and phenotypic characterization of the cell-division protein CdpA. Gene 342:189-197.

Altermann, E., W. M. Russell, M. A. Azcarate-Peril, R. Barrangou, B. L. Buck, O. McAuliffe, N. Souther, A. Dobson, T. Duong, and M. Callanan. 2005. Complete genome sequence of the probiotic lactic acid bacterium Lactobacillus acidophilus NCFM. Proc. Natl. Acad. Sci. USA 102:3906-3912.

Azcarate-Peril, M. A., J. M. Bruno-Barcena, H. M. Hassan, and T. R. Klaenhammer. 2006. Transcriptional and functional analysis of oxalyl-coenzyme A (CoA) decarboxylase and formyl-CoA transferase genes from Lactobacillus acidophilus. Appl. Environ. Microbiol. 72:1891-1899.

Azcarate-Peril, M. A., O. McAuliffe, E. Altermann, S. Lick, W. M. Russell, and T. R. Klaenhammer. 2005. Microarray analysis of a two-component regulatory system involved in acid resistance and proteolytic activity in Lactobacillus acidophilus. Appl. Environ. Microbiol. 71:5794-5804.

Barefoot, S. F., and T. R. Klaenhammer. 1983. Detection and activity of lacticin B, a bacteriocin produced by Lactobacillus acidophilus. Appl. Environ. Microbiol. 71:4925-4929.

Barrangou, R., M. A. Azcarate-Peril, T. Duong, S. B. Conners, R. M. Kelly, and T. R. Klaenhammer. 2006. Global analysis of carbohydrate utilization by Lactobacillus acidophilus using cDNA microarrays. Proc. Natl. Acad. Sci. USA 103:3816-3821. 
Buck, B. L., E. Altermann, T. Svingerud, and T. R. Klaenhammer. 2005. Functional analysis of putative adhesion factors in Lactobacillus acidophilus NCFM. Appl. Environ. Microbiol. 71:8344-8351.

Buck, B. L., M. A. Azcarate Peril, and T. Klaenhammer. 2008. Role of autoinducer-2 on the adhesion ability of Lactobacillus acidophilus. J. Appl. Microbiol. In press.

Carr, F. J., D. Chill, and N. Maida. 2002. The lactic acid bacteria: A literature survey. Crit. Rev. Microbiol. 28:281-370.

Cesena, C., L. Morelli, M. Alander, T. Siljander, E. Tuomola, S. Salminen, T. Mattila-Sandholm, T. Vilpponen-Salmela, and A. von Wright. 2001. Lactobacillus crispatus and its nonaggregating mutant in human colonization trials. J. Dairy Sci. 84:1001-1010.

Champagne, C. P., N. J. Gardner, and D. Roy. 2005. Challenges in the addition of probiotic cultures to foods. Crit. Rev. Food Sci. Nutr. 45:61-84.

Cui, X., and G. A. Churchill. 2003. Statistical tests for differential expression in cDNA microarray experiments. Genome Biol. $4: 210$.

Duong, T., R. Barrangou, W. M. Russell, and T. R. Klaenhammer. 2006. Characterization of the tre locus and analysis of trehalose cryoprotection in Lactobacillus acidophilus NCFM. Appl. Environ. Microbiol. 72:1218-1225.

Fabret, C., and J. A. Hoch. 1998. A two-component signal transduction system essential for growth of Bacillus subtilis: Implications for anti-infective therapy. J. Bacteriol. 180:6375-6383.

Fonseca, F., C. Beal, and G. Corrieu. 2000. Method of quantifying the loss of acidification activity of lactic acid starters during freezing and frozen storage. J. Dairy Res. 67:83-90.

Gorke, B., and J. Stulke. 2008. Carbon catabolite repression in bacteria: Many ways to make the most out of nutrients. Nat. Rev. Microbiol. 6:613-624.

Grangette, C., S. Nutten, E. Palumbo, S. Morath, C. Hermann, J. Dewulf, B. Pot, T. Hartung, P. Hols, and A. Mercenier. 2005 Enhanced antiinflammatory capacity of a Lactobacillus plantarum mutant synthesizing modified teichoic acids. Proc. Natl. Acad. Sci. USA 102:10321-10326.

Hegde, P., R. Qi, K. Abernathy, C. Gay, S. Dharap, R. Gaspard, J. E. Hughes, E. Snesrud, N. Lee, and J. Quackenbush. 2000. A concise guide to cDNA microarray analysis. Biotechniques 29:548-562.

Hisbergues, M., M. Magi, P. Rigaux, J. Steuve, L. Garcia, D. Goudercourt, B. Pot, J. Pestel, and A. Jacquet. 2007. In vivo and in vitro immunomodulation of Der p 1 allergen-specific response by Lactobacillus plantarum bacteria. Clin. Exp. Allergy 37:12861295.

Hutkins, R. 2006. Cultured dairy products. Pages 107-114 in Microbiology and Technology of Fermented Foods. Blackwell Publishing, Ames, Iowa.

Kunz, C., S. Rudloff, W. Baier, N. Klein, and S. Strobel. 2000 Oligosaccharides in human milk: Structural, functional, and metabolic aspects. Annu. Rev. Nutr. 20:699-722.

Law, J., G. Buist, A. Haandrikman, J. Kok, G. Venema, and K. Leenhouts. 1995. A system to generate chromosomal mutations in Lactococcus lactis which allows fast analysis of targeted genes. J. Bacteriol. 177:7011-7018.

Leonard, B. A. B., and A. Podbielski. 1999. Emerging densitydependent control systems in Gram-positive cocci. Pages 315-331 in Cell-Cell Signaling in Bacteria. G. M. Dunny and S. C. Winans, ed. American Society for Microbiology, Washington, DC.

Liu, H., S. Tarima, A. S. Borders, T. V. Getchell, M. L. Getchell, and A. J. Stromberg. 2005. Quadratic regression analysis for gene discovery and pattern recognition for non-cyclic short time-course microarray experiments. BMC Bioinformatics 6:106.

Marcotte, H., S. Ferrari, C. Cesena, L. Hammarstrom, L. Morelli, G. Pozzi, and M. R. Oggioni. 2004. The aggregation-promoting factor of Lactobacillus crispatus M247 and its genetic locus. J. Appl. Microbiol. 97:749-756.
Mattila-Sandholm, T., P. Myllarinen, R. Crittenden, G. Mogensen, R. Fonden, and M. Saarela. 2002. Technological challenges for future probiotic foods. Int. Dairy J. 12:173-182.

McAuliffe, O., R. J. Cano, and T. R. Klaenhammer. 2005. Genetic analysis of two bile salt hydrolase activities in Lactobacillus acidophilus NCFM. Appl. Environ. Microbiol. 71:4925-4929.

Monnet, V., M. Nardi, A. Chopin, M. C. Chopin, and J. C. Gripon. 1994. Biochemical and genetic characterization of PepF, an oligopeptidase from Lactococcus lactis. J. Biol. Chem. 269:3207032076 .

Ouwehand, A. C., E. M. Tuomola, S. Tolkko, and S. Salminen. 2001. Assessment of adhesion properties of novel probiotic strains to human intestinal mucus. Int. J. Food Microbiol. 64:119-126.

Pastar, I., I. Tonic, N. Golic, M. Kojic, R. van Kranenburg, M. Kleerebezem, L. Topisirovic, and G. Jovanovic. 2003. Identification and genetic characterization of a novel proteinase, PrtR, from the human isolate Lactobacillus rhamnosus BGT10. Appl. Environ. Microbiol. 69:5802-5811.

Peltoniemi, K., E. Vesanto, and A. Palva. 2002. Genetic characterization of an oligopeptide transport system from Lactobacillus delbrueckii subsp. bulgaricus. Arch. Microbiol. 177:457-467.

Reid, G., M. E. Sanders, H. R. Gaskins, G. R. Gibson, A. Mercenier, R. Rastall, M. Roberfroid, I. Rowland, C. Cherbut, and T. R Klaenhammer. 2003. New scientific paradigms for probiotics and prebiotics. J. Clin. Gastroenterol. 37:105-118.

Russell, W. M., and T. R. Klaenhammer. 2001. Efficient system for directed integration into the Lactobacillus acidophilus and Lactobacillus gasseri chromosomes via homologous recombination. Appl. Environ. Microbiol. 67:4361-4364.

Sanders, M. E., and T. R. Klaenhammer. 2001. Invited review: The scientific basis of Lactobacillus acidophilus NCFM functionality as a probiotic. J. Dairy Sci. 84:319-331.

Savijoki, K., H. Ingmer, and P. Varmanen. 2006. Proteolytic systems of lactic acid bacteria. Appl. Microbiol. Biotechnol. 71:394-406.

Shah, N. P. 2000. Probiotic bacteria: Selective enumeration and survival in dairy foods. J. Dairy Sci. 83:894-907.

Smeianov, V. V., P. Wechter, J. R. Broadbent, J. E. Hughes, B. T. Rodriguez, T. K. Christensen, Y. Ardo, and J. L. Steele. 2007. Comparative high-density microarray analysis of gene expression during growth of Lactobacillus helveticus in milk versus rich culture medium. Appl. Environ. Microbiol. 73:2661-2672.

Spellerberg, B., E. Rozdzinski, S. Martin, J. Weber-Heynemann, and R. Lutticken. 2002. rgf encodes a novel two-component signal transduction system of Streptococcus agalactiae. Infect. Immun. 70:2434-2440.

Sturme, M. H., J. Nakayama, D. Molenaar, Y. Murakami, R. Kunugi, T. Fujii, E. E. Vaughan, M. Kleerebezem, and W. M. de Vos. 2005. An agr-like two-component regulatory system in Lactobacillus plantarum is involved in production of a novel cyclic peptide and regulation of adherence. J. Bacteriol. 187:5224-5235.

Tatusov, R. L., E. V. Koonin, and D. J. Lipman. 1997. A genomic perspective on protein families. Science 278:631-637.

Titgemeyer, F., and W. Hillen. 2002. Global control of sugar metabolism: A gram-positive solution. Antonie Van Leeuwenhoek 82:59-71.

Tuomola, E., R. Crittenden, M. Playne, E. Isolauri, and S. Salminen. 2001. Quality assurance criteria for probiotic bacteria. Am. J. Clin. Nutr. 73(Suppl):393S-398S.

Vinciotti, V., R. Khanin, D. D'Alimonte, X. Liu, N. Cattini, G. Hotchkiss, G. Bucca, O. de Jesus, J. Rasaiyaah, C. P. Smith P. Kellam, and E. Wit. 2005. An experimental evaluation of a loop versus a reference design for two-channel microarrays. Bioinformatics 21:492-501.

Vishwanath, S., and R. Ramphal. 1984. Adherence of Pseudomonas aeruginosa to human tracheobronchial mucin. Infect. Immun. 45:197-202. 